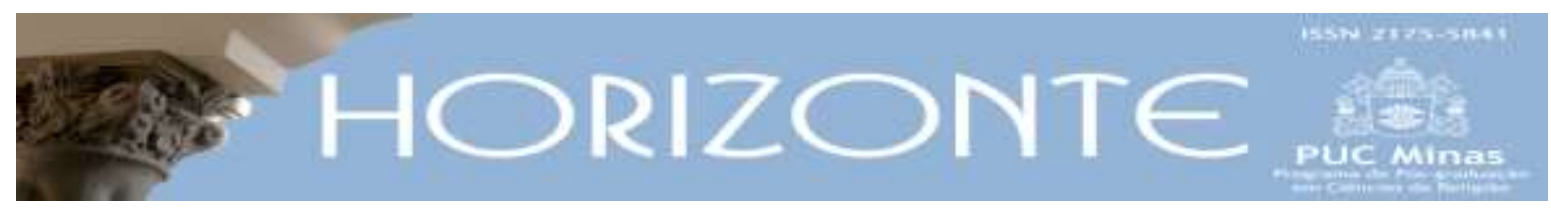

Dossiê: Desafios teológicos do Pluralismo Religioso - Artigo original (c) (i)

DOI - 10.5752/P.2175-5841.2015v13n40p1755

\title{
Paradigma Pluralista: mirando al futuro
}

\author{
Pluralist paradigm: looking ahead
}

José Maria Vigil*

\begin{abstract}
Resumen
El autor presenta en primer lugar la situación paradójica de estancamiento y de urgencia que reviste la situación que actualmente atraviesa la teología del pluralismo religioso. Desde una perspectiva abierta de ciencias de la religión, pasa revista (VER) a la situación del pluralismo cultural-religioso en la sociedad occidental, en el Islam, y en la Iglesia Católica. Pasa a continuación a JUZGAR sobre estas situaciones ponderando la dificultad que reflejan para dar pasos nuevos hacia el pluralismo: la dificultad propia de los cambios de paradigma en general, la propia de los cambios de paradigma religiosos, y la dificultad específica del paradigma pluralista, señalando también que en términos de cambio de paradigma, no es posible avanzar linealmente, sino sólo apoyándose simultáneamente en argumentos múltiples, desde distintos enfoques disciplinares o paradigmáticos. En la tercera parte (ACTUAR), viendo la situación global a la luz de estas dificultades, trata de apuntar posibles pasos adelante que habría que preparar para dar el salto al paradigma pluralista, pasos que agrupa en dos frentes, el epistemológico y el teologico, sin abandonar la perspectiva de ciencias de la religión en que se coloca en todo momento.
\end{abstract}

Palabras clave: Paradigma, pluralismo, exclusivismo, inclusivismo, epistemología.

\begin{abstract}
:
The author presents, in the first place, the paradoxical situation of both stagnation and urgency, which the theology of religious pluralism is going through. From an open perspective of the sciences of religion, he first shows (to SEE) the situation of religious pluralism, cultural and religious, in western society, in Islam, and in the Catholic Church. Then, in the second part (to JUDGE), situations are evaluated taking into account the difficulty they represent to start on a new step to pluralism. Such difficulties are those inherent in changes of paradigm in general, those of a change in religious paradigms, and the specific difficulty of a pluralistic paradigm, stating as well, that in terms of a change of paradigm, it is not possible to advance straightly, but only simultaneously relying on multiple arguments, from different disciplinary or paradigmatic approaches. In the third part (to ACT), analyzing the global situation in light of these difficulties, he tries to show possible previous steps to take so as to plunge into the pluralistic paradigm, steps he groups in two, epistemological and theological, without abandoning the perspective of the sciences of religion on which he stands at all times.
\end{abstract}

Keywords: Paradigm, pluralism, exclusivism, inclusivism, epistemology.

Artigo recebido em 14 de agosto 2015 e aprovado em 20 de novembro 2015.

* Possui doutorado em Educación, con especialidad en mediación pedagógica - Universidad La Salle, de San José de Costa Rica (2010). País de Origem: Panamá. E mail: josemariavigil@gmail.com

Horizonte, Belo Horizonte, vol. 13, n. 40, p. 1755-1789, out./dez. - ISSN 2175-5841 


\section{Introducción}

La actual coyuntura del tema de la teología del pluralismo cruza por una etapa de estancamiento por una parte, y de urgencia, por otra.

El estancamiento es efecto subsiguiente a los pontificados conservadores de Juan Pablo II y Benedicto XVI, que si supusieron un freno y hasta un retroceso a los avances del Concilio Vaticano II, mucho más se opusieron a la eventualidad de que se dieran nuevos pasos teóricos hacia adelante, como el que suponía la emergente teología (pluralista) del pluralismo religioso. Juan Pablo II se instaló decididamente en el inclusivismo oficial, incluso con carácter restrictivo (TEIXEIRA, 2007)', rechazando en su magisterio las posiciones germinalmente pluralistas que el llamado "reinocentrismo" de la teología de la liberación comportaba CASALDÁlIGA; VIGIL (1993) ². El 6 de agosto de 2000, el cardenal Ratzinger publicó la Instrucción Dominus Iesus, que radicalizó la posición inclusivista rechazando autoritariamente (TORRES QUEIRUGA, 2014)3 cualquier apertura a las posiciones pluralistas. Esta coyuntura doctrinal de signo conservador en la Iglesia Católica, sobre todo la citada Dóminus Iesus, afectó también muy negativamente al ambiente ecuménico e inter-religioso en general, produciéndose una fuerte tensión y un efectivo enfriamiento de las relaciones ecuménicas, produciéndose el estancamiento de que hablamos, en el campo teórico o teológico investigativo y creativo. Para la inquisición católica de la Congregación para la Doctrina de la $\mathrm{Fe}, \mathrm{CDF}_{4}$, la teología del pluralismo religioso se convirtió en el nuevo

\footnotetext{
${ }^{1}$ De hecho, a pesar del cambio radical que el Concilio Vaticano II supuso, el principio del extra Ecclesiam nulla salus, se mantuvo en la documentación oficial de la Iglesia y fue incorporado al Catecismo de la Iglesia Católica en un supuesto «sentido positivo» (no 846). Cfr. Teixeira (2007).

${ }^{2}$ Cfr, a modo de símbolo, los números 17 y siguientes de su Redemptoris Missio (1990). La teología de la liberación, con un claro arraigamiento bíblico, redescubrió el Reino de Dios como la Utopía de Jesús mismo, con lo que se superaba de raíz el eclesiocentrismo: una Iglesia descentrada de sí misma y toda ella al servicio del Reino... La encíclica trató de reducir de alguna manera el Reino a la Iglesia, en cuanto que "el Reino no puede ser separado ni de Cristo ni de la Iglesia». CASALDÁLIGA; VIGIL (1993).

${ }^{3}$ Torres Queiruga (2014) ha dicho en voz alta lo que tantos piensan: durante los dos últimos pontificados Josef Ratzinger «trató de imponer - con claridad y, digámoslo, con intransigente energía - una teología muy concreta y determinada. No es preciso recordar los numerosos conflictos con los teólogos ni las duras condenas y exclusiones que propició, para reconocer que no respetó el pluralismo, sino que tendió a identificar la defensa de la fe con la profesión de una sola teología, la que él sostenía. Una identificación que no sólo es siempre ilegítima en cualquier teólogo, sino que, apoyada en el poder, resultó injusta y gravemente empobrecedora para la teología católica.

${ }^{4}$ En el «perfil» que la propia CDF publica en su web (vatican.va), reivindica con orgullo, ya en su primer párrafo, que ella es la misma institución fundada por Pablo III en 1542 con el nombre de Romana y Universal Inquisición.
} 
enfant terrible de la teología (RATZINGER, 1997, p. 17)5, el campo minado sobre el que recaerían las condenas a los teólogos creativos que han osado hacer cualquier propuesta que apuntase más allá del impuesto inclusivismo. Y ahí llevamos casi dos décadas de estancamiento, de impase y de improductividad teológica en este campo.

Por otra parte, la coyuntura política internacional de los últimos años testimonia una conflictividad entre bloques culturales y religiosos que no hace sino profundizarse y agravarse, hasta el punto de que podamos hablar del surgimiento de una gran ola de violencia explícitamente religiosa internacional. Las viejas palabras de Gandhi, publicitadas luego por Hans Küng, de que no habrá paz en el mundo mientras no haya paz entre las religiones, vuelven a resonar hoy, y su recuerdo salta al primer plano de la actualidad noticiosa internacional. Esta ola de violencia no es sólo cultural, o intercultural -que lo es, con toda claridad-; es también religiosa, e inter-religiosa, fruto de una relación conflictiva no sólo entre las culturas sino también entre sus religiones. Esta violencia llega a adquirir dimensiones históricamente inéditas, con un goteo continuo de muertes, atentados, explosiones detonadas por atacantes suicidas en lugares públicos concurridos, incluso lugares religiosos... que hacen cada vez más perceptible la urgencia política y humanitaria de solucionar a esta violencia. Y es por todo esto por lo que decimos que, por implicación, la teología del pluralismo adquiere esta misma "urgencia”, a pesar de su aparente estancamiento.

Como se deja ver, no estamos hablando de "teología del pluralismo" en el sentido eclesiástico del término, sino en un sentido bien más amplio, ubicado en el campo de las ciencias de la religión, y tanto en el aspecto del pluralismo como en el de interculturalidad. Es desde esta perspectiva global desde la que queremos hacer un balance sobre la situación actual de este tema científico religioso que decimos se

\footnotetext{
${ }^{5}$ La llamada teología pluralista de las religiones se había desarrollado progresivamente ya desde los años 50; sin embargo, sólo ahora se ha situado en el centro de la conciencia cristiana. De algún modo, esta conquista ocupa hoy -por lo que respecta a la fuerza de su problemática y a su presencia en los diversos campos de la cultura- el lugar que en el decenio precedente correspondía a la teología de la liberación. Además, se une de muchas maneras con ella, e intenta darle una forma nueva y actual. RATZINGER (1997, p.17).
} 
ha convertido en urgencia política y humanitaria en la sociedad mundial. Esta urgencia civil mundial es un motivo añadido a la urgencia netamente teológica y religiosa que, ya de por sí, debiera impulsarnos a dar nuevos pasos que nos saquen de ese estancamiento en que estamos en medio de la intensa crisis de violencia inter-religiosa en la que todavía estamos.

Adoptaremos la tradicional metodología latinoamericana tripartita.

\section{VER}

La mirada a nuestra situación actual podemos desglosarla en varias miradas sectoriales, escogiendo algunos bloques socio-religioso-culturales más representativos ${ }^{6}$.

\subsection{La situación de pluralismo cultural-religioso en la sociedad civil occidental}

Resulta un lugar común afirmar que la sociedad occidental es pluralista. Sabemos sin embargo que, históricamente, no lo ha sido. El actual bloque cultural occidental viene de unas sociedades anteriores que para nada fueron pluralistas y tolerantes, sino sociedades imperiales e imperialistas en períodos recurrentes de su historia, sociedades que han tenido religión pública, religiones de Estado, y organismos especializados de represión contra la pluralidad religiosa (citemos solamente la Inquisición). El pasado de Occidente no es, en manera alguna, pluralista.

Pero un proceso de transformación se inició hace siglos, por el que, a través de graves conflictos religiosos, sociales y políticos, y de largas guerras, se llegó a un

\footnotetext{
${ }^{6}$ Cuando estamos redactando este estudio recibimos una "Carta Abierta Coletiva em Repúdio à Intolerância Religiosa", que afirma que el año 2015, aun a la altura del mes de julio, fecha de la carta, «tem sido marcado por inúmeras manifestações de intolerancia religiosa, especialmente em relação a pessoas fieis de religiões de natriz afro-brasileira»... La problemática de la violencia religiosa está presente por doquier. Firman la Carta Abierta ocho entidades: ABA, ABHR, ACSMR, ANPTECRE, ANPUH, GTHRR/ANPUH, ISER y SOTER.
} 
armisticio. La Paz de Augsburgo, en 1555, puede ser el momento simbólico del inicio de un nuevo nivel de convivencia socio-religiosa occidental.

I padri conciliari [del Vaticano II] che, il 28 ottobre 1965, votarono la dichiarazione Nostra aetate, avevano per riferimento l'immaginario del classico cuius regio eius et religio, con cui la pace di Augusta (1555) si era illusa di poter mettere fine alle guerre fra cattolici e luterani in Europa. In altri termini: salvo che per eccezioni risapute (Stati Uniti, case study di scuola), essi condividevano l'idea che in ogni nazione del mondo si desse una religione decisamente prevalente sulle altre, mentre il pluralismo delle fedi rappresentava una condizione eccentrica rispetto a quella regola. I decenni seguenti sono andati in tutt'altra direzione ( SALVARANI, 2015, p. 83-103).

En efecto, la sociedad occidental ha ido evolucionando hacia un pluralismo religioso muy acentuado y -teóricamente al menos- irreversiblemente aceptado. Obviamente, subsisten los problemas, y muchos, pero son la excepción que confirma una regla de convivencia que, desde hace ya varios siglos, se recoge en la mayor parte de las constituciones políticas de los estados occidentales, que reconoce plenamente la libertad religiosa como un derecho humano inalienable (la religión es asunto privado de la persona), que consagra la separación entre Religión y Estado así como la aconfesionalidad y la laicidad de las instituciones políticas, etc. Ya no se trata de un Occidente compuesto por "naciones cristianas", católicas o protestantes, sino de unos países oficialmente laicos, a veces laicistas incluso, con una gran variedad de posiciones religiosas -incluyendo las opciones religiosas del ateísmo, de la increencia, y la de los "no afiliados"-. En no pocos de esos países están superados también los tiempos de laicismo y de anticlericalismo: hoy día es común en Occidente el reconocimiento y el tratamiento respetuoso y favorable del fenómeno religioso como un activo humano a acoger con respeto y con neutralidad laica positiva.

Podemos decir que, a pesar de las siempre presentes tensiones entre las instituciones políticas y las religiosas en el día a día de la actualidad política de cada país, a pesar de los conflictos de intereses que nunca faltan, se puede decir que el pluralismo religioso hoy día es un patrimonio cultural asumido en Occidente, al 
menos hasta un cierto grado. No ha sido fácil el camino de estos varios siglos pasados, ni ha sido incruento; pero tanto sufrimiento está dando sus frutos. Debajo de esta convivencia religiosamente pluralista, la sociedad occidental lleva en su trasfondo ideológico una "teología laica (pluralista) del pluralismo religioso", que valora el derecho individual y colectivo a la libertad religiosa, y que legitima y protege la convivencia de las diferentes religiones y opciones religiosas o areligiosas. En este punto concreto del pluralismo, creo que podemos decir -con tanta humildad como satisfacción- que la sociedad civil religiosa occidental está más avanzada que las mismas religiones presentes en su seno.

\subsection{La conciencia de pluralismo cultural-religioso en el Islam}

Lamentablemente el nombre del Islam está siendo hoy día vinculado demasiadas veces con noticias de violencia por motivos culturales y religiosos. Podemos decir que después de un buen tiempo como de calma y silencio, se ha dado en el Islam un reavivamiento, una rebeldía, un "Resurgimiento islámico" (HUNTINGTON, 1997, p.280) 7 a nivel planetario, que representa "la última fase del reajuste de la civilización islámica ante Occidente” (HUNTINGTON , 1997, p.280).

A nivel internacional mundial estamos todos siendo testigos de una ola de violencia de signo $\mathrm{u}$ origen religioso que hace siglos que no conocíamos (BINGEMER, 2001, p.296; CASPAR, 1996, p. 253)8. La aparición del terrorismo religioso internacional podemos datarla simbólicamente en el 11 de septiembre de 2001, con el atentado a las Torres Gemelas de Nueva York y la subsiguiente invasión y guerra contra Afganistán por parte de EEUU en venganza. Ahí comenzó una serie de atentados terroristas internacionales, en distintos países, como una

\footnotetext{
${ }^{7}$ Samuel Huntington (1997, p.208) defiende que debe ser escrito con «R» mayúscula, porque se refiere a un acontecimiento histórico sumamente importante que afecta a una quinta parte o más de la humanidad, lo que al menos es tan transcendental como la Revolución americana, la Revolución francesa o la Revolución rusa, y es semejante y comparable a la Reforma protestante de la sociedad occidental.

${ }^{8}$ Sobre la relación entre el Islam y la violencia véase Bingemer (2001, p.296) (org.) y también, Caspar (1996). Xavier Pikaza (2015) sostiene: «Mahoma creou un estado musulmán coa súa palabra e a espada. El mesmo tivo que loitar contra infieis para defenderse e conquistar A Meca, de maneira que a política e a guerra, razón de estado e violencia militar, constitúen elementos importantes da Umma». Paraconstruir la Umma, «Mahoma utilizou medios mesmo moi violentos (matou muitos xudeus e contrarios).
} 
verdadera novedad histórica. Hay que destacar que no se trata simplemente de actos de terrorismo político, sino de actos de terrorismo con presencia también de fuertes motivaciones religiosas. Quienes los ejecutan no son militantes movidos por una ideología política o económica, sino fervorosos creyentes encendidos por el celo por la gloria de Dios, que deciden ofrendar su vida e inmolarse a sí mismos como mártires, para causar de esa forma el mayor daño posible a los infieles, a los enemigos de Dios.

Llevábamos década y media lidiando con este tipo de violencia terrorista religiosa, cuando he aquí que hemos asistido a una escalada de la misma, con la aparición sorpresiva del Estado Islámico (EI, o DAESH, según su acrónimo en árabe) en los confines de Siria, Turquía e Irak, el 19 de junio de 2014. Desde entonces, recibimos casi semanalmente noticias de ejecuciones por causa de esa violencia religiosa en forma de decapitaciones, crucifixiones, amputaciones, lapidaciones, arrojamiento de homosexuales al vacío desde el tejado de los edificios altos, rehenes quemados vivos dentro de una jaula, o ahogados en una piscina dentro también de una jaula, siendo todo ello filmado en video con lujo de detalles y con técnica exquisita, y difundido profusamente por internet. No hace falta que ponderemos más la extensión e intensidad que ha alcanzado en los últimos meses esta ola de violencia religiosa y reacción contra-terrorista, que se abate sobre la actualidad internacional en la que los atentados de París de noviembre de 2015 sólo son un episodio más de una lista por ahora sin final.

Pues bien, toda esta violencia, como decimos, es de origen religioso, y está causada por una mentalidad religiosa de tipo exclusivista. Las personas que sufren esta tentación son personas religiosas, muy religiosas incluso, y con frecuencia fundamentalistas. Consideran que su religión es la única verdadera, la única querida por Dios, y por tanto, la única legítima. Todas las demás religiones -así piensan- son creaciones humanas, suplantaciones de la verdadera religión, u obra del Diablo, que está en lucha contra Dios. Serían, en definitiva, religiones falsas, o idolátricas, o satánicas, que el Dios verdadero no podría sino desear que sean 
aniquiladas. La gloria de Dios pediría entablar una "guerra santa" contra los infieles y contra sus religiones. De ahí los llamados a la violencia apelando a la religión.

Esta violencia, llamada yihadista (MELLONI, 2003, p.398; KEPEL, 2001)99, motivada por ese celo por la gloria de Dios, no parece no ser la violencia del mal menor, la de la justicia restaurativa que trata de infligir el menor daño posible, sino al contrario. Abu Bakr al Bagdadi, el califa del autoproclamado EI, "ha llamado en repetidas ocasiones a golpear a los "infieles" allí donde se encuentren. En marzo de 2015 el mensaje de un movimiento yihadista tunecino que suele anunciar los ataques instó a llevar a cabo nuevos atentados contra turistas poniendo énfasis en los viajeros estadounidenses, británicos, franceses e israelíes: "Atropéllalos [a los turistas] con el coche, después de haber cambiado la matrícula y haberte cubierto el rostro. Sedúcelos en carreteras, hoteles, clubes de baile y bares. Asesínalos en playas, ahógalos en el mar o envenénalos en las carreteras proporcionándole comida contaminada, rómpeles el cráneo con una piedra o asfíxialos con una almohada en sus habitaciones. Luego toma su dinero y su equipaje como botín y márchate sigilosamente"'“10.

Insistamos: esta actitud de violencia religiosa tan agresiva sólo es posible dentro de un paradigma religioso exclusivista. El problema-raíz de la violencia inspirada por la propia religión es la autocomprensión religiosa exclusivista. Ésta es una de las causas principales del clima de violencia religiosa que se ha instalado en el escenario internacional actual. Y esta es la razón por la que afirmamos que la difusión de una nueva conciencia religioso-epistemológica pluralista en las religiones que todavía se entienden a sí mismas de un modo auto-exclusivista,

\footnotetext{
${ }^{9}$ Sobre el debatido concepto de la yihad, remitamos a un experto de Javier Melloni (2003, p.398). Puede verse también Kepel (2001).

${ }^{10}$ Cuando los turistas se convierten en blanco de la yihad, El Mundo, 28 de marzo de 2015. El 22 de septiembre de 2014 los yihadistas del El difundieron un llamado internacional a sus seguidores «a matar a los ciudadanos de los países que se han sumado a la coalición impulsada por EEUU contra los yihadistas: "Si puedes matar a un infiel estadounidense o europeo, especialmente al vengativo y sucio francés, o un australiano o un canadiense, o cualquiera de los infieles que libran la guerra, incluidos los ciudadanos de los países que entraron en la coalición contra el El, entonces confía en Dios y mátalo de cualquier manera", dijo el portavoz del grupo, Abu Mohamed al Adnani a Diario El Comercio.
} 
sobre todo las que están protagonizando la violencia internacional actual, es una urgencia social, política y humanitaria.

El profesor Bernard Haykel, de la universidad de Princeton dice:

los occidentales se preguntan si el islam necesita una reforma, si podría beneficiarse de algo similar a la Reforma protestante en Europa, que en último término condujo a la Ilustración y al Siglo de las Luces, de los que todos somos herederos y beneficiarios. Lo que este planteamiento olvida a menudo es que aquella reforma fue un período largo y extremadamente violento que provocó la muerte de millones de europeos, en especial durante la Guerra de los Treinta Años (1618-1648). Y lo cierto es que, en realidad, el islam ya está experimentando una reforma en la actualidad, y todos nosotros somos sus testigos"11 ( HAYKEL, 2015).

Por su parte, la pensadora y activista somalí, Ayaan Hirsi Ali ya ha presentado "cinco tesis" para dicha reforma, aun sin pretender ser "un Lutero para el Islam”(EL PAÍS, 2015).

Como es sabido, el proceso que va desde el exclusivismo o inclusivismo al pluralismo, implica todo un "cambio de paradigma", que conlleva una "relectura pluralista” de la propia religión. Es una reinterpretación global de todo el conjunto de su patrimonio simbólico. Realizar con éxito este proceso hermenéutico de transformación implicado en la aceptación del paradigma pluralista (una verdadera metamorfosis), es lo que estoy diciendo que, ante el actual escenario de violencia religiosa internacional, es una urgencia política, civil y humanitaria ${ }^{12}$.

\subsection{La situación del pluralismo en la Iglesia Católica}

\section{Al hablar de "pluralismo" en la Iglesia Católica no nos estamos refiriendo necesariamente a la Teología del Pluralismo religioso (TPR), sino, más}

\footnotetext{
${ }^{11}$ Bernard Haykel (2015). Xavier Pikaza (2015, p.12) aboga también por la necesidad de la Reforma en el Islam: "Os musulmáns han de asumir, en conxunto, un tipo de llustración, é dicir, de racionalidade, pero non ao modo de occidente, senón ao seu".

12 Junto a esta evaluación de la situación del Islam, cabría referirse igualmente a la situación de violencia permanente judío-ilsámica, para constatar cómo detrás del conflicto se mueven argumentaciones concretamente veterotestamentarias, leídas como criterio político o geográfico a favor de unos o de otros... En el Parlamento israelí, los textos bíblicos son invocados como arma indiscutible para reivindicar la ocupación de la tierra, la negación del estado palestino, la definición de las fronteras.
} 
ampliamente, al paradigma epistemológico-cultural del pluralismo. La TPR es sólo una expresión de este paradigma epistemológico-cultural civil.

Hemos dicho más arriba que en el Occidente actual, moderno y postilustrado, a pesar de las excepciones, y con las tensiones y conflictos que nunca faltan, la aceptación del paradigma pluralista es un dato cultural e ideológico que forma parte de las sociedades civiles occidentales, incorporado a los supuestos convivenciales recogidos en las constituciones políticas y en los pactos y acuerdos políticos internacionales del más alto nivel. La Iglesia Católica está en Occidente como en su propio ambiente cultural, hasta el punto de que lo que hoy llamamos Occidente es en realidad la herencia de lo que fue la "Cristiandad occidental"(HUNTINGTON, 1997, p.208, 52ss). Aunque la Iglesia Católica se opuso frontalmente a la consecución de los derechos y libertades modernas en el proceso de la Ilustración y la modernidad (GUTIÉRREZ, 1958, p. 1073), trató luego de adaptarse a la situación por medio de Concordatos con los diferentes estados, tratando de conseguir una posición lo más cercana posible a lo que habían sido los antiguos estados confesionales. Sólo con el Concilio Vaticano II la Iglesia Católica se reconcilió finalmente con esas "libertades modernas" y con la secularización del Estado moderno, aceptándolas sin reticencias e incorporándolas a su propia visión de la sociedad. En el Concilio ${ }^{13}$ la Iglesia aceptó concretamente la libertad religiosa, la individual y la colectiva, la secularización del Estado moderno, la convivencia en igualdad social con otras religiones y hasta con el ateísmo. Pero entiéndase bien: aceptó esta nueva visión -en la que va incluido el paradigma pluralista- para la sociedad civil, no para la Iglesia misma.

Es lo que ocurre con todo el conjunto de las libertades modernas: libertad de conciencia, libertad de pensamiento, libertad de expresión, libertad de asociación, igualdad de la mujer, sociedad igualitaria sin clases ni estamentos discriminatorios...: la Iglesia Católica acepta que estén en vigencia en la sociedad, y

\footnotetext{
${ }^{13}$ Concretamente en los documentos Dignitatis Humanae, sobre la libertad religiosa, Nostra Aetate, sobre las religiones no cristianas, y también en la Declaración Pastoral Gaudium et Spes sobre la Iglesia en el mundo actual.
} 
piensa sinceramente que ése es el mejor orden social posible en esta etapa de la historia, pero sólo en la sociedad civil; en el interior de la Iglesia no se aceptan ni entran a estar en vigor esos derechos ni libertades modernas.

Pues bien, lo que concretamente llamamos "paradigma pluralista” religioso forma parte del conjunto de las libertades modernas. La aceptación de la legitimidad de la pluralidad religiosa en Occidente, como hemos dicho, es una conquista ya relativamente antigua, conseguida mediante luchas sociales para la superación de las guerras de religión, mediante la elaboración de una nueva base social jurídica libre de toda adherencia teológica (el yusnaturalismo, el contractualismo social ...) (VIGIL, 1975). Desde entonces Occidente acepta omnímodamente la pluralidad religiosa, tanto a nivel individual (libertad de conciencia) como colectivo (libertad social religiosa), y acepta en pie de igualdad a todas las religiones (pluralismo religioso). La aceptación de este nuevo paradigma pluralista, ocurrió concretamente gracias al paso adelante que se dio desde el paradigma exclusivista al inclusivista: abandonamos la doctrina según la cual extra Ecclesiam nulla salus y pasamos a reconocer que también hay salvación fuera del cristianismo, aunque matizamos a continuación que esa salvación que encontramos fuera es una participación de la nuestra, o sea, que estrictamente hablando no hay ninguna otra fuente de salvación fuera del cristianismo.

A nivel teórico interno de la Iglesia Católica, a nivel de doctrina y de teología, la posibilidad del paradigma pluralista se encuentra bloqueada desde la Declaración Dóminus Iesus (DI) del cardenal Ratzinger. Concretamente, la DI (Congregación para la Doctrina de la fe, 2002, passim) impone taxativamente, estos límites:

Es inadmisible para un cristiano pensar que la revelación cristiana sea limitada o incompleta y que pudiera ser enriquecida con la revelación presente en otras religiones (6). En las demás religiones no puede hablarse de verdadera fe, sino simplemente de creencias; fe teologal sólo la puede haber entre nosotros los 
cristianos (7). Todo lo que puedan contener de bueno las Escrituras Sagradas de otras religiones (excepto el judaísmo) proviene de Cristo, no de sí mismas (8). Igualmente, todo lo que el Espíritu obra en las personas, en los pueblos, en las culturas y en las religiones se refiere necesariamente a Cristo, y no tiene valor evangélico, sino simplemente de "preparación para el Evangelio" (12). Pudiera haber alguna otra mediación entre Dios y los seres humanos, más allá del cristianismo, pero sólo cobrarían significado y valor por la mediación de Cristo, fuera de la cual no se puede ni siquiera pensar en una hipotética acción salvífica de Dios (14). Un cristiano no puede aceptar reconocer a otras religiones el carácter de caminos de salvación (21). Los no cristianos se hallan en una situación salvífica gravemente deficitaria (22).

Parece obvio que con esta autocomprensión del cristianismo no es posible llegar muy lejos en el camino del diálogo intercultural e inter-religioso ${ }^{14}$. Esta autocomprensión niega las bases teóricas, psicológicas y epistemológicas del diálogo. De hecho, a los pocos años de la DI, ha sido su propio autor, convertido ya en papa Benedicto XVI, quien ha reconocido off the official record la imposibilidad del diálogo inter-religioso: desde esa visión teológica, es decir, desde el paradigma inclusivista, no es posible dialogar inter-religiosamente: las religiones sólo pueden dialogar en el terreno cultural (PERA, 2008)15.

Aunque aquella confesión de Benedicto XVI pasó medio desapercibida quizá por el medio no "oficial magisterial" elegido para hacerla pública-, resulta claro el carácter traumático emblemático que reviste: se trata del reconocimiento de una derrota, del levantamiento de acta del impase ante el que se encuentra un

\footnotetext{
${ }^{14}$ Tampoco del ecumenismo, que no estamos tratando aquí. Recuérdese al respecto la negativa a reconocer el nombre de Iglesias a las Iglesias protestantes... A pesar de su talante bien diferente, el papa Francisco, en su significativa visita a la Iglesia Valdense de Turín, el 22 de junio de 2015, se ha encontrado con la herida pendiente: "Noi valdesi siamo una chiesa, dovete riconoscerci come tale...", ha reclamado el moderador. "Fratello Francesco, non capiamo che cosa significhi l'espressione del Concilio che ci definisce comunità e non chiese. Vuol dire che noi siamo una chiesa a metà, una chiesa non chiesa? Siamo una chiesa, peccatrice, certo, ma chiesa di Gesù Cristo, da lui giudicata e salvata".

${ }^{15}$ Se podría citar numerosos pasajes, desde su discurso a los representantes de algunas comunidades musulmanas en Colonia, el 20 de agosto de 2005, a la Carta abierta a los 138 intelectuales islámicos del 13 de octubre de 2007. Pero donde lo proclamó más contundentemente fue en la Prefazione al libro de Marcello Pera, Perché dobbiamo dirci cristiani (2008): “Il terreno del dialogo non è la religione in sé, ma la cultura che è frutto della tradizione religiosa". También fue publicado este Prefacio, íntegramente, en Il Corriere della Sera (2008).
} 
pensamiento teológico que se confiesa incapaz de dialogar con otras religiones. Desde sus presupuestos ideológicos, no encuentra una forma de superar su propia posición fagocitadora de las demás religiones sin renunciar a sus propios principios -así le parece-. Tratándose de la religión identificadora de la civilización occidental -que, como hemos dicho, puede ser tenida, a pesar de todas las dificultades, como una de las civilizaciones más pluralistas y tolerantes-, estamos ante una enorme paradoja, un signo de la enorme distancia que se ha creado entre el cristianismo y su propia sociedad cultural, Occidente. A nivel socio-político internacional, Occidente se debate con los conflictos inter-religiosos ajenos tratando de aportar soluciones ubicadas netamente dentro del paradigma pluralista, y poco se ve ayudado por parte del cristianismo, que en la Iglesia Católica oficial concretamente se bate en retirada reconociendo una supuesta imposibilidad del diálogo inter-religioso. A nivel civil y popular, la sociedad occidental ha llegado a posiciones ampliamente pluralistas, dejando atrás, a mucha distancia ideológica, las obsoletas posiciones inclusivistas o cuasi-exclusivistas del cristianismo oficial.

\subsection{Para un balance}

Nos atreveríamos a decir que la coyuntura internacional actual de reavivamiento de la tensión y el conflicto entre los bloques culturales o civilizacionales, a pesar de las inevitables bases económicas que siempre están ahí en juego, tiene hoy una marcada dimensión religioso-cultural. No están en juego en conflicto- sólo intereses económicos, sino, sobre todo formas profundas de entender el mundo y las visiones religiosas que las inspiran, que están marcadas por comprensiones de la pluralidad incapaces de superar la infravaloración de los otros y el afán proselitista y hegemónico a nivel civil y de bloques culturales. No son sólo recursos económicos y cuotas de poder lo que causa los conflictos, sino sobre todo formas de entender la religiosidad, la verdad, la revelación de Dios, la elección divina, la presencia de Dios en la configuración jurídica de la sociedad, la 
confesionalidad o la laicidade de la sociedad, la libertad religiosa, la libertad de conciencia, la pluralidad religiosa de la sociedad... Son precisamente los temas esenciales de la que llamamos "teología del pluralismo": una teologización sobre la realidad plural de las religiones, y una reflexión sobre la posibilidad y el fundamento de su convivencia y comprensión mutua. Nos atrevemos a decir que uno de los grandes temas sobre los que la sociedad humana actual está necesitando hacer una actualización y una reflexión profunda sobre ese conjunto de temas e implicaciones que desde hace unas pocas décadas estamos llamando como "teología del pluralismo religioso", de cara a renovar y adaptar su posición religiosa adaptándola a las exigencias de la altura de los tiempos. Las actitudes exclusivistas, proselitistas, conquistadoras, inclusivistas, las convicciones de ser la única religión verdadera, o la religión-destino de las demás religiones, o la religión incluidora de todas las demás... actitudes y convicciones que han sido comunes a lo largo de la historia pasada, no son ya de recibo en la nueva situación del mundo, y que la pervivencia de estas actitudes y convicciones es también causa de la enorme tensión religiosa que estamos viviendo ${ }^{16}$.

Es urgente -con una urgencia religiosa, civil, política y hasta humanitariaque las religiones accedan a una nueva visión, al "paradigma emergente", al "paradigma pluralista" concretamente, que las haga capaces de convivir en paz y en colaboración proactiva, lo que no será posible sólo mediante una decidida voluntad de cooperación en la práctica ${ }^{17}$. Mientras no se dé esta renovación del componente teórico-teológico-paradigmático, todos los esfuerzos por el diálogo meramente prácticos resultarán inútiles. Es de interés social, político y humanitario que las religiones cambien de modo de pensar unas de otras. El mundo, la humanidad necesita que las religiones accedan a una nueva visión.

\footnotetext{
${ }^{16}$ Si estas afirmaciones resultaran fuertes o sorprendentes para la teología, debería ésta confrontarse con ellas asumiéndolas como parte del conflicto fe/ciencia, que hoy, obviamente, persiste. La teología oficial inclusivista -como puede verse en sus documentosignora totalmente el punto de vista de las ciencias de la religión, de la sociología, de la interculturalidad, las ciencias bio-evolutivas, etc. ${ }^{17}$ El llamado «diálogo de vida», muy importante y valioso, pero insuficiente.
} 
Ahora bien, acceder a esta nueva visión tiene sus dificultades. Es lo que vamos a constatar al "juzgar" esta realidad conflictiva y de impase que acabamos de "ver".

\section{JUZGAR}

Estamos diciendo que dentro de la comprensión de las relaciones entre las religiones, el paso a una nueva visión, el cambio hacia un paradigma pluralista, a pesar de sus enorme importancia e interés, tiene sus grandes dificultades, de todo tipo. Necesitamos explicitarlas para poder derivar de ahí la prognosis de los próximos pasos que debieran ser implementados para posibilitarlo.

\subsection{Están en primer lugar las dificultades propias de todo cambio de paradigma}

Basta recordar a Thomas Kuhn. Según él, la “ciencia normal” avanza en los períodos ordinarios sin dificultad, pero, con el tiempo, entra en períodos turbulentos, en los que el paradigma científico compartido hasta entonces por la comunidad científica deja de estar claro, apareciendo en él un número creciente de "anomalías" antes nunca percibidas, que le restan credibilidad y lo hacen cada vez menos funcional y más incómodo para fungir como explicación global. Es en ese tiempo de crisis previo a las revoluciones de la ciencia, cuando la comunidad científica se encuentra más insatisfecha: el viejo paradigma parece cada vez más incapaz de dar cuenta de una explicación que satisfaga la situación actual, y por otra parte lo nuevo, lo que parece estar gestándose entre los científicos más intuitivos, no acaba de nacer, y no logra ser expresado de un modo convincente para la mayoría. Más avanzada la crisis, hacen aparición ya propuestas de formulación que aumentan el desconcierto de muchos de los científicos más tradicionales, que no están en capacidad de romper con su paradigma anterior.

En materia de religiones y pluralismo estamos hoy día en ese momento evocado por esta alusión que acabamos de hacer a la teoría de los paradigmas 
(KUHN, 2000, 112ss): la vieja visión exclusivista e inclusivista hace aguas por todas partes y no posibilita una sana convivencia entre las religiones; los "epiciclos" que se proponen son claramente insuficientes; aparecen ya propuestas intuitivas nuevas que son rápidamente rechazadas -con violencia incluso- por los miembros más conservadores de la comunidad cognitiva y por las instituciones afectadas, y se alcanza un grado máximo de efervescencia, con tensión, conflicto y enfrentamientos, y "miles de víctimas", en el ámbito concreto de realidad de violencia internacional. Son las dificultades propias de todo cambio de paradigma.

\subsection{Están en segundo lugar las dificultad específica del cambio de paradigma de religión}

Me refiero no a cambios de paradigma dentro de la religión, relativos a cualquiera de los elementos o niveles que se dan dentro de ella, sino al cambio de paradigma que se da actualmente en la concepción misma de qué sea la religión y cómo se va a transformar.

Es ya un lugar común decir que estamos en un nuevo "tiempo axial", después de aquel otro, evocado por Karl Jaspers, que dio origen a la conciencia religiosa moderna, de la que todavía hoy continuamos siendo deudores. Se trata pues de un cambio, de una transformación inédita, cuyo precedente -si se pudiera considerar tal- se dio hace miles de años... y que nos va a colocar, por vía de metamorfosis (MARTÍN VELASCO, 1999), en un nuevo tipo de religiosidad que nos es imposible imaginar.

En materia de religiones y de pluralismo religioso, estamos en esa tesitura histórica: convulsiones, conflictos, resistencias, avances y simultáneamente retrocesos ante la desorientación que produce la crisis de lo antiguo, y por otra parte lo que está viniendo y no sabemos qué es. No tenemos antecedentes a disposición. 


\subsection{Y están también las dificultades propias del paradigma pluralista}

a) En primer lugar la dificultad de que se trata del cambio no de un elemento, o de una rama, una sección... sino de un cambio "de paradigma”, es decir, un cambio de la infraestructura teológica y epistemológica de todo un edificio de conocimiento, que va a resultar por tanto enteramente transformado y reformulado. Cambiar de paradigma no es una revisión, ni un aggionarmento, ni una actualización... Es una "mutación radical de la autocomprensión" de la propia religión (TORRES QUEIRUGA, 2005, p. 151), una "relectura"18, una reconstrucción subsiguiente a la deconstrucción de un edificio venerable tenido incluso por inmutable... Es el cambio mayor a que podemos referirnos. Por eso, es comprensible que la resistencia que se concite sea muy fuerte.

b) En el cristianismo concretamente, este posible paso hacia el paradigma pluralista nos sorprende ubicados en el paradigma inclusivista, mientras otras religiones están en el estadio exclusivista. La diferencia no es tanta, como podría pensarse equivocadamente, pues el inclusivismo no de deja de ser, estructuralmente, un exclusivismo atemperado, pero exclusivismo en el fondo. La mayor parte de las religiones venimos del exclusivismo, en el que hemos estado "desde el comienzo de los tiempos" o, más realistamente, desde el origen o surgimiento de las propias religiones. Esas religiones nacieron en el exclusivismo, en él se gestaron, y en su atmósfera y dentro de su marco construyeron todo su edificio de su patrimonio simbólico. Todos los elementos que lo constituyen llevan la impronta genética -por implicación- del exclusivismo, incompatible con el pluralismo...

\footnotetext{
${ }^{18}$ El subtítulo de mi libro en la edición brasileña reza así: Para uma releitura pluralista do cristianismo. Lo que algunos ven como amenaza en el paradigma pluralista es que, como todo nuevo paradigma, postula y provoca una nueva relectura total del conjunto, precisamente porque se trata de un nuevo «paradigma».
} 
Por ello, este cambio de paradigma implica reconstruir también el conjunto del edificio simbólico en el cual está ubicado. La revelación respectiva tal como ha sido ancestralmente entendida, el significado de la tradición religiosa, los dogmas heredados, verdades tenidas hasta ahora como tabú o declaradas recientemente como "verdades irreformables"... son otras tantas dificultades sobreañadidas al cambio concreto del paradigma pluralista, que explican sobradamente la resistencia de que es objeto este cambio paradigmático.

c) Una dificultad propia de estos grandes cambios de paradigma religiosos es la de que, normalmente, no es posible dar el paso adelante por una argumentación lineal y única, sino que es necesario "empujar" el paso desde varias perspectivas y accesos; sólo el conjunto de las evidencias de las varias perspectivas logra imponerse sobre las resistencias que se dan en el itinerario argumentativo de uno solo de los accesos. En concreto: para una persona o comunidad que esté convencidamente instalada en una visión teológica exclusivista o inclusivista, no es posible dar el paso hacia el pluralismo, porque desde la base en la que se apoya, el pluralismo resulta inaceptable; sólo será posible tratando de transitar argumentaciones complementarias desde por ejemplo- la historia de las religiones, el estudio de la evolución de la construcción teórica de los dogmas, el análisis de los intereses en juego bajo las doctrinas teológicas (lo que llamamos la "hermenéutica de la sospecha"(VIGIL, 2006, p. 469)19, el punto de vista de las víctimas de los imperialismos justificados desde nuestra religión... Sólo a partir de estos puntos de empuje múltiples (y con dificultades, a pesar de todo) es posible reunir fuerzas suficientes para dar el paso adelante del abandono de una visión paradigmática anterior tan afincada en nuestra manera ancestral de ver. Es decir: no basta "estudiar el tema" ("un" tema) para poder dar el salto, sino que es necesario un proceso de posibilitación

\footnotetext{
${ }^{19}$ Dedico todo un capítulo a este tema en mi libro Teología del pluralismo religioso (2006).
} 
cognitiva apuntalado desde todo el conjunto de la visión humana vigente en esa determinada comunidad cognitiva.

Es por esta necesaria multiplicidad de accesos por lo que, normalmente, la opinión pública de la sociedad civil capta intuitivamente la necesidad y la inevitabilidad del paradigma pluralista mejor que la opinión teológico-institucional religiosa, encerrada frecuentemente en el fanal de las referencias escriturísticas y teológicas de la propia religión. Un testimonio significativo al respecto puede ser el del historiador de las civilizaciones Arnold Toynbee, que aun reconociendo su condición de no teólogo, se manifiesta convencido de la necesidad de

purgar nuestro cristianismo de la tradicional creencia cristiana de que el cristianismo es único. (...) Es una creencia inherente al cristianismo mismo, un rasgo congénito que forma parte de la herencia del judaísmo que recibieron el cristianismo y el islam. Debemos hacerlo, si hemos de purgar al cristianismo de la intolerancia que sigue a la creencia de que el cristianismo es único.

Por difícil que sea purgar al cristianismo de su cará cter exclusivo, parece indispensable que los cristianos realicen esa hazaña espiritual, y lo parece por una serie de razones. La principal de ellas está en que el exclusivismo es un estado pecaminoso del espíritu. Tra tase del pecado del orgullo... un archipecado (TOYNBEE, 1997, p.121-123).

d) Está también la dificultad de la duración del proceso. No se cambia de paradigma religioso de un día para otro, ni toda la sociedad religiosa lo capta ni lo asimila a la vez... Occidente atravesó varios siglos de conflictos y guerras, mucho dolor y miles de muertes, hasta que logró dar un estatus de convivencia pacífica a las religiones. La Reforma que algunos musulmanes piden para el Islam no se alcanzará con un proceso menos doloroso que el que Occidente ha vivido. La misma Iglesia Católica, que ya dio en el Vaticano II el gran paso de la superación del exclusivismo, se debate en el doloroso trance de dar el paso definitivo hacia el pluralismo o continuar siendo disfuncional a una de las necesidades evolutivas más perentorias de la especie humana. 
En ese proceso estamos. La persecución del Vaticano frente a la reflexión teológica creativa ${ }^{20}$, el autoritarismo de la Dóminus Iesus y de la CDF, el silenciamiento de teólogos... lo muestran. Dupuis murió como consecuencia de los sufrimientos que le infligió su descalificación oficial, a pesar de que él, precisamente, intentaba conciliarlo todo en una obediencia casi imposible (BURROWS , 2014).

e) Nadie sabe decir qué dificultades tendrá que afrontar el Islam si un día quisiera asumir el paradigma pluralista... Tal vez, por ahora, la posibilidad no puede siquiera ser planteada. Pero tampoco era posible hace 60 años en el seno de la Iglesia Católica postular un paradigma siquiera inclusivista... Son los pensadores del Islam quienes deben hacer su aportación, para bien no sólo del Islam, sino de todas las religiones. Esa aportación de los pensadores y líderes del Islam forma parte hoy día de la urgencia política, social y humanitaria de que hablamos.

\section{ACTUAR}

\subsection{Por qué hay que dar ya nuevos pasos}

\section{a) Hay que dar nuevos pasos porque estamos en un mundo nuevo}

Desde tiempos inmemoriales, las religiones han vivido en su propio ambiente cultural particular, sin contactos entre ellas. La evolución social de los últimos tiempos nos han llevado a una sociedad global, planetizada,

\footnotetext{
${ }^{20}$ Los teólogos que a pesar de todo han sido sinceros y valientes y han hecho pública su reflexión teológica favorable al cambio de paradigma en materia de pluralismo, necesitan el coraje esperanzado que animaba en una situación semejante a Garrigou-Lagrange, cuando escribía: "Me castigan hoy por escribir cosas que se enseñarán mañana". O como escribió Wellhausen en 1883, cuando fue rechazada por las Iglesias protestantes su famosa "hipótesis de los cuatro documentos": "Sé que las Iglesias rechazarán primero mis teorías durante cincuenta años, pero luego las admitirán en su credo con sutiles argumentos". En efecto, unos 60 años más tarde, en 1943, el Pío XII publicó la encíclica Divino Afflante Spiritu, en la que decía que ya habían pasado los tiempos del miedo a la investigación, y que los biblistas católicos debían utilizar para sus estudios todas las ayudas de las ciencias modernas. En este año del 60 aniversario de la muerte de Teilhard, podemos recordar que, durante toda su vida, no pudo publicar, por prohibición de la Santa Sede, todos los volúmenes que después de su muerte, entregados a una mano no eclesiástica, han sido publicados y traducidos a un gran número de idiomas en un éxito editorial inimaginable.
} 
profundamente inter-penetrada cultural y religiosamente, en la que todas las religiones se ven obligadas a convivir permanentemente, unas ante otras. Y por otra parte, casi coincidiendo exactamente con el siglo XXI, hemos entrado en una fase de la historia caracterizada por un cambio de eje en la conflictividad social, que habría pasado de las ideologías económico-políticas a los bloques humanos culturales $^{21}$ (HUNTINGTON, 1997 passim), lo que no es una afirmación sociológica teórica, sino que nos ofrece todos los días buenas pruebas en las noticias de conflictos internacionales, atentados suicidas, amenazas y muertes efectivas con un componente fuertemente religioso.

Estas dos transformaciones socioculturales citadas, y la forma como de hecho la sociedad internacional no consigue gestionar la convivencia inter-religiosa pacífica en este nuevo marco, evidencian que la antigua autocomprensión que las religiones forjaron de sí mismas y de su relación con las demás religiones, ha quedado obsoleta y es manifiestamente incapaz para gestionar la convivencia internacional de los bloques culturales que esas mismas religiones determinan e inspiran. Todo apunta a que estamos viviendo actualmente una transformación profunda, como la "gran transformación" (ARMSTRONG, 2007, p.591) del tiempo axial al que Karl Jaspers se refirió (JASPERS, 1953); un segundo tiempo axial que va a transformar, de nuevo, profundamente, nuestra religiosidad. La autocomprensión tradicional que las religiones gestaron en un mundo rural, tribal, premoderno, precientífico y fragmentado, no es funcional a un mundo moderno, científico, culto y mundializado; por el contrario, propicia la desconfianza, el recelo, el desprecio, la animosidad, la consideración de los otros creyentes como infieles, como adherentes a una religión inferior, sin revelación, en "situación salvífica gravemente deficitaria”, no elegida por Dios, o como concurrente contra el destino que Dios ha dado a nuestra religión de ser la religión hegemónica. Aunque cada una con sus matices, las actuales autocomprensiones que las religiones tienen de sí mismas en su relación con las demás no posibilitan la buena convivencia, son una

${ }^{21}$ Es la tesis central del libro de Huntington (1997, p.208). 
fuente de roces y de enfrentamientos. Estamos en ese tránsito, en esa nueva "gran transformación”.

Pues bien, ya es muy sabido: "no habrá paz entre los pueblos mientras no haya paz entre las religiones”, y no se dará tal paz entre las religiones mientras éstas no rehagan esa su autocomprensión, lo que equivale a decir: no habrá paz en el mundo, mientras las religiones no modifiquen su propia teología sobre el pluralismo religioso.

\title{
b) Hay que dar nuevos pasos porque estamos en un momento de encrucijada
}

Lo dice muy bien Seshagiri Rao, desde el hinduismo:

\begin{abstract}
Estamos en un punto crucial en la historia. Para las religiones del mundo ha llegado el momento de buscar un nuevo horizonte. Los modelos de pensamiento pasados, que consideraban a la gente como grupos cerrados, ya no son válidos. Las categorizaciones de las personas de otras religiones como paganas, gentiles, infieles, o bárbaros... deben de ser rechazadas totalmente. Detrás de nosotros hay una historia de siglos de confrontaciones religiosas, y delante, la oportunidad de la paz, la cooperación y el dia logo. Las tradiciones religiosas son ú tiles en muchas formas, pero el exclusivismo religioso es de mente estrecha. Tenemos que vivir en un mundo que tiene hindúes, budistas, cristianos, musulmanes, sikhs, jainistas, confucionistas, taoístas, shintoi stas, etc., grandes comunidades que poseen magníficos credos. La fidelidad a nuestras respectivas tradiciones religiosas no debe minar nuestra lealtad para con la humanidad. Actualmente, las religiones mundiales tienen la oportunidad y la responsabilidad de cooperar una con otra en la promoción de la unidad humana y la paz mundial. (SESHAGIRI RAO, 2010, p. 153).
\end{abstract}

Más difícil es para las religiones encontrar el momento oportuno (kairótico) para acometer cambios profundos de actitud o de doctrina, en cuestiones que han sido muy tradicionales o que han sido tenidas por intocables, dogmáticas o esenciales. Ahí las religiones quedan muy frecuentemente rehenes de sí mismas, sin atreverse a dar un paso adelante que inicie la adopción del paradigma emergente. En realidad, ni sabemos cómo hicieron nuestras propias religiones para dar los pasos que en el pasado supusieron aquellos cambios radicales que ya asumieron. Los católicos concretamente bien pueden testimoniar que el abandono 
del exclusivismo, que había sido una doctrina oficial y solemnemente profesada durante más de milenio y medio, por la que se había perseguido y hasta ejecutado a quienes no la profesaran, fue abandonada durante la celebración del Concilio Vaticano II de un modo medio pacífico, intuitivo, dejándose llevar del ambiente psicológico del momento kairótico que se estaba viviendo.

Hoy la diferencia es que somos conscientes del corsé doctrinal que llevamos puesto, y que son muchas las voces que claman conscientemente por el cambio necesario. Hoy no se trata de algo pacífico, intuitivo, o algo que, simplemente, está "en el espíritu del tiempo", sino de que estamos tomando conciencia de la necesidad de liberarnos de formas históricas de pensamiento que hemos heredado respetuosamente pero que no responden ya a estos tiempos, que no tienen por qué atarnos e impedirnos tomar las decisiones que hoy se nos han hecho obvias. Tenemos derecho a ser creadores de historia, y a no ser víctimas de la historia que hicieron nuestros padres en la fe. Lo dice también Seshagiri:

\begin{abstract}
Las verdades espirituales son de carácter eterno, pero las costumbres y las prácticas sociales y culturales cambian segu $n$ las exigencias del momento y las circunstancias. Muchas religiones en la historia han cambiado su postura sobre muchos temas; por ejemplo, las religiones han modificado sus posturas sobre la esclavitud, la discriminación racial, la situación de la mujer, la centralidad del rito o la actitud hacia la ciencia. Ha llegado el momento de sobrepasar el exclusivismo religioso y la discriminación. Los ríos deben de fluir y las personas religiosas madurar; de otro modo, se estancan. Tenemos que ser creadores de la historia, no sus víctimas. No nacimos para vivir dentro de lí mites estrechos. Tenemos que replantear nuestros problemas en este nuevo contexto de mucha gente de otras fes.( SESHAGIRI RAO, p. 152-153.)
\end{abstract}

El momento especial o de encrucijada que estamos viviendo no es el de una coyuntura internacional determinada, sino el de un momento evolucionario crítico. Las grandes religiones, que ayudaron a la supervivencia de la especie humana durante varios milenios, entran en declive a medida en que la humanidad se adentra en la transformación cultural que está transitando, en este nuevo tiempo axial, y se hacen disfuncionales a la convivência y sobre todo a la creatividad 
necesaria para la maduración de la especie. En un determinado momento, pueden pasar a ser obstáculo más que ayuda para la humanidad. Para lo cual, la vitalidad de la especie tiene mecanismos evolutivos para despojarse de lo que amenaza su supervivencia. El creciente conflicto entre las religiones, y el desapego de una buena parte de la sociedad frente a ellas, pueden ser signo de la crisis evolutiva que nuestra especie está viviendo también respecto de su dimensión espiritual. Está por ver si, efectivamente, las religiones -o algunas de ellas- tienen todavía capacidad para reconvertirse en factores de maduración y evolución de nuestra especie.

\section{c) Hay que dar nuevos pasos porque la vieja visión nos está haciendo daño}

"Los ríos deben fluir, y las personas religiosas deben madurar", y el curso de la historia religiosa va a seguir evolucionando por más que algunos lo intenten impedir. Ya Carlos Jung advertía lo frecuente que es en el campo religioso que las personas no tengan flexibilidad psicológica para comprender que lo que ha sido bueno, y hasta muy bueno, con el tiempo puede dejar de serlo, y hasta puede pasar a ser nocivo, dañino:

El ser humano tiende constantemente a olvidar que lo que una vez fue bueno no tiene por qué serlo eternamente. Continúa observando los antiguos usos que antaño fueron buenos, después de volverse malos. Solamente consigue librarse de este engaño a través de grandes sacrificios e indecible sufrimiento; sólo entonces se da cuenta de que lo que antaño fue bueno, quizás ahora haya envejecido y ya no lo sea. Así ocurre tanto en cuestiones de gran envergadura como en detalles pequeños. Los usos y costumbres de la niñez, antaño tan sublimemente buenos, a duras penas pueden abandonarse incluso cuando su carácter dañino lleva tiempo demostrado. Se puede decir lo mismo, pero a escala gigantesca, de los cambios históricos de actitud. Una actitud colectiva es equivalente a una religión, y los cambios de religión constituyen uno de los capítulos más dolorosos de la historia del mundo. En este sentido nuestra época sufre una ceguera que no tiene igual. Pensamos que sólo tenemos que declarar incorrecto e inválido un artículo de fe para deshacernos psicológicamente de todos los efectos tradicionales del cristianismo y del judaísmo. Olvidamos por completo que la religión de los últimos dos mil años es una actitud psicológica, una forma y manera definida de adaptación al mundo, que conforma un esquema cultural definido y crea una atmósfera en la que los rechazos intelectuales no influyen en absoluto (JUNG, 2005, p. 505). 
En materia de teología del pluralismo, el exclusivismo y el inclusivismo son posturas que fueron naturales en su tiempo, que cumplieron su papel para la pervivencia y el fortalecimiento de las religiones; del inclusivismo concretamente no se niega su buena intención (TORRES QUEIRUGA, 2005, p.151), y la significativa solución que aportó para las aporías que el exclusivismo planteaba. Pero en este mundo concreto del siglo XXI, ambas posiciones han tocado techo hace tiempo, y han perdido la plausibilidad que en algún tiempo tuvieron; hoy aparecen como modelos claramente obsoletos, insostenibles, y sobre todo dañinos.

El exclusivismo casi siempre ha llevado a las religiones a actitudes imperialistas, coloniales, hegemónicas, agresivas... "en nombre de Dios” y "para su mayor gloria”. Las cruzadas, las guerras santas, las conquistas para extender la fe, la violencia cruenta contra los infieles, para instaurar el Reino de (nuestro) Dios en la tierra... sólo son posibles en religiones que se autocomprenden a sí mismas desde un modelo exclusivista. El complejo de superioridad (KNITTER, 2005, p.242), la infravaloración de las otras religiones, la cerrazón en el propio modo de ver y creer, el rechazo de las aportaciones de las demás religiones, la incapacidad para dialogar inter-religiosamente... son actitudes derivadas característicamente del inclusivismo.

Entretanto, dependiendo del contexto social, ocurren varias cosas: una hemorragia constante y masiva de personal abandona las religiones que se resisten a adoptar formas religiosas de pensamiento y de espiritualidad acordes con la visión pluralista de la sociedad actual civil, o bien, otras personas, sobre todo personas jóvenes de profunda religiosidad son atraídas a posiciones fundamentalistas y ultras, dispuestas a dar literalmente la vida en la tarea de implantar sobre los infieles, a sangre y fuego, el proyecto de una sociedad religiosa exclusiva a la mayor gloria de Dios.

Por lo que toca a la Iglesia Católica, las ciencias de la religión constatan claramente que la actual posición cerradamente inclusivista nos hace daño a 
nosotros mismos, hace daño a las demás Iglesias y religiones, que se resienten de nuestra actitud antiecuménica, y hace daño a tantas personas católicas que se ven obligadas a exiliarse internamente de la propia Iglesia, así como hace daño a la sociedad humana misma, en cuanto que la priva de la fuerza espiritual que aportaría una población católica de mente abierta, pluralista, colaborativa, valoradora de todas las riquezas espirituales y tradiciones religiosas presentes en la sociedad.

\title{
d) Hay que dar nuevos pasos porque es una urgencia civil, política y humanitaria
}

Es el momento de hacerlo presente en este punto conclusivo: como venimos diciendo, el debate teórico dentro de la teología del pluralismo religioso no es un asunto interno de las religiones, una problemática intestina de sus instituciones, sin repercusión externa ni interés social. Al contrario: que se extienda una conciencia pluralista, intercultural e inter-religiosa en las bases de las religiones y en sus cúpulas directivas, es, en la actual situación de violencia religiosa es una verdadera urgencia política, que debería ser propuesta a las Naciones Unidas como un objetivo político prioritario y como una línea de acción educativa y concientizadora a nivel mundial.

En otro lugar he afirmado:

\begin{abstract}
A la vista de las cifras de víctimas de la persecución religiosa, creemos que esa urgencia política es también una urgencia humanitaria. La actual violencia religiosa no necesita sólo de respuestas militares y políticas, sino también de políticas educativas y concientizadoras. Más que responder con violencia a los grupos religiosos fundamentalistas agresivos, hay que ayudarles a abrir su mente, a reconsiderar críticamente sus Sagradas Escrituras y sus tradiciones religiosas doctrinales y morales, a actualizar su visión teológica compatibilizándola con los tiempos actuales... y a gozarse del maravilloso don de la biodiversidad religiosa, la omnipresente ubicuidad del Espíritu, que promueve todas las manifestaciones espirituales de una Humanidad que está siempre en su busca. A los sectores religiosos violentos, no hay que arrojarles bombas, sino libros, ayuda educacional y científica, planes de desarrollo cultural, iniciativas de
\end{abstract}


diálogo inter-religioso, actualización y modernización de sus ministerios teológicos y doctrinales. Frente al "choque de civilizaciones" 22 , que en su mayor parte es también "choque de religiones", corresponde en primer lugar a las religiones el ponerse a trabajar en la reeducación y el diálogo necesarios, en ambos lados del conflicto. Pero queremos hacer desde aquí un llamado a los órganos mayores de la actual "gobernanza mundial" -la ONU en primer término, pero también todas las instituciones públicas y privadas preocupadas por la convivencia intercultural y la paz mundial- a hacer todo lo posible por establecer una "Alianza de Civilizaciones, Culturas y Religiones". Para la ONU concretamente, esta urgencia debiera resultar mandatoria (III Simposio Internacional de Teología, UIA, sept. 2015).

Que se extienda una conciencia paradigmáticamente pluralista es algo de interés público y social. Significa una maduración, un crecimiento espiritual y un salto adelante en el desarrollo evolutivo de la humanidad. Es una responsabilidad de todos el colaborar a ese objetivo, sobre todo por parte de las religiones.

\subsection{Qué pasos podrían ser los próximos 23}

1) Por más que a veces se piense lo contrario, los obstáculos mayores que las religiones como instituciones y las personas religiosas encuentran en para realizar cambios paradigmáticos dentro de su fe, son obstáculos de naturaleza epistemológica, que suelen pasar desapercibidos para muchos creyentes. El mundo religioso, las religiones en general, suelen ser deudoras de una epistemología tradicional, muy prendida de la metafísica clásica objetivista e idealista, que conlleva supuestos acríticos que bloquean la posibilidad misma de tales cambios.

Pero la visión epistemología actual ofrece planteamientos, conocimientos que ayudan a deshacer esos obstáculos. Enumeramos algunas orientaciones que pueden ser útiles para capacitar a las religiones para dar el cambio paradigmático necesario hoy día:

\footnotetext{
${ }^{22}$ Según la famosa obra de Samuel Huntington.

${ }^{23}$ Seguimos moviéndonos en el campo amplio de las ciencias de la religión. Una elaboración estrictamente teológica sería objeto de otro estudio.
} 
a) las religiones deben ser ayudadas con urgencia a asimilar la superación de la epistemología mítica, superación que la sociedad civil ya ha realizado. Epistemología mítica llamamos a aquella que hace del mito el principal recurso para la fundamentación y la interpretación de sus principales verdades. Algunas religiones ya han hecho un examen crítico de sus Escrituras y han llegado a reconocer los “mitos" -en un sentido de la palabra enteramente positivo- como un género literario y como un instrumento, valioso epistemológicamente hablando, pero sin confundirlo nunca con una información descriptiva, objetiva o narrativa.

b) las religiones deben ser ayudadas a aceptar y reconocer el carácter construido de la realidad religional. Deben aceptar el estudio crítico de sus propios orígenes y de sus propias leyes de evolución histórica, para asimilar lo que hoy es ya patrimonio común de las ciencias de la religión, a saber: el carácter construido de la religión. La religión que siga pensándose como caída del cielo, como revelada ad pedem literae, con sus propias normas esculpidas por Dios sobre piedra, resultará rehén de la ignorancia sobre sus propios orígenes, y no será capaz de tomar decisiones que impliquen cambios sobre esos elementos o normas que juzgará ser disposiciones directamente divinas.

c) a los creyentes -y sobre todo los teólogos/as- le debe ser familiar el conocimiento del carácter especial del lenguaje religioso como un lenguaje metafórico, que se refiere a unas realidades, las religiosas, que no se acomodan a un tratamiento denotativo directo, exacto, descriptivo, dador de información objetiva, contrastable y mensurable. Y ya es sabido que las metáforas varían en su capacidad 
de evocación en la medida en que su fundamento -el subconsciente cultural colectivo- va transformándose constante e inevitablemente.

d) el lenguaje religioso debe ser renovado con la toma de conciencia de los nuevos planteamientos epistemológicos sobre la objetividad... El lenguaje actual, como la misma cultura actual, es post-metafísico. Ya no concebimos la verdad como aquella adaequatio rei et intellectus, como una correspondencia que se daría entre el contenido de nuestras afirmaciones y una realidad objetiva -ya sea en este mundo, o en un segundo piso metafísico- que respaldaría nuestras afirmaciones... Hoy urge una toma de conciencia que posibilite la deconstrucción epistemológica de la supuesta objetividad metafísica del lenguaje...

e) las religiones deberían plantearse el aceptar el ejemplo del hinduismo, que se reconoce a sí mismo como "una religión sin verdades"(GHANDI, 2006)24... Se trata de una orientación epistemológica diferente, que libera a la religión para lo que le es propio: el cultivo de la experiencia religiosa, dejando libre el ámbito de la verdad, que deberá ser alcanzada por otros órganos especializados (a la religión no le compete ayudar a la humanidad a alcanzar la verdad, sino a vivir su espiritualidad).

Con la epistemología tradicionalmente presente en las religiones (objetivista, dualista, idealista, metafísica, de verdades eternas, inmutables, reveladas...), las religiones se encuentran paralizadas, rehenes de sí mismas, atadas por su propia epistemología obsoleta, incapaces de dar un paso adelante tanto en el paradigma pluralista como en los demás campos paradigmáticos que están en

\footnotetext{
24 "Por suerte o por desgracia, el hinduismo no tiene ningún credo oficial. Si se me pidiera definir el credo hindú, diría simplemente: buscar la verdad por medios no violentos". Gandhi (2006, p.15).
} 
transformación actualmente 25 . Neutralizados los obstáculos epistemológicos, la superación de los obstáculos teológicos resultará mucho más fácil.

2) Refiriéndonos al plano más teológico, podemos recordar que la literatura teológica ad hoc viene señalando la dificultad mayor que ofrecen algunos elementos teológicos, que deben por eso mismo ser confrontados y revisados con prioridad, para facilitar la reelaboración teológica.

Por ejemplo, es común afirmar que el tratado teológico que más urge revisar es el de la revelación (TORRES QUEIRUGA, 1987; VIGIL, 2005). El antiguo planteamiento de la revelación como una fuente de conocimiento exterior, enteramente sobrenatural, venida directamente de Dios desde un segundo piso, que nos transmite informaciones o conocimientos que el cielo quiere compartir con nosotros para orientarnos de un modo infalible y divino de cara nuestra actuación, resulta paralizante, y funciona como antídoto a la más mínima capacidad de una toma de decisión de cambio paradigmático (WARRAQ, 2003) ${ }^{26}$.

La conceptuación negativa del pluralismo religioso, como fruto del pecado del orgullo humano, como castigo impuesto por Dios a la Humanidad (en Babel), es otro de los supuestos acríticos inconscientes que bloquean la reflexión teológica pluralista, y que hoy se evidencian como claramente contrarios a la sensibilidad actual.

El concepto de elección ${ }^{27}$ puede ser considerado emblemático respecto de la actual necesidad de deconstrucción de elementos y doctrinas que, por más que hayan sido venerables y hayan cumplido su papel, hoy son ya inaceptables y

\footnotetext{
${ }^{25}$ Hay bastante bibliografía sobre los principales cambios de paradigma actualmente en curso. Véase esta bibliografía, precisamente de materiales en línea: servicioskoinonia.org/BibliografiaNuevosParadigmas.pdf

${ }^{26}$ Ibn Warraq (2003) llega a sostener que "tal vez el peor legado de Mahoma haya sido su insistencia en que el Corán es la palabra literal de Dios, y por ende incuestionablemente verdadera, ya que de ese modo impidió toda posibilidad de libertad de pensamiento y de nacimiento de nuevas ideas, sin los cuales el mundo islámico es absolutamente incapaz de progresar y entrar en el siglo XXI"

${ }^{27}$ El tema de la "elección" no figura siempre con ese nombre. Así, la doctrina del "Destino Manifiesto" de Estados Unidos es obviamente una versión moderna del concepto bíblico de elección.
} 
necesitan, no tanto una actualización o reinterpretación, cuanto una simple y llana superación: su eliminación y su olvido (TORRES QUEIRUGA, 2001, p.70)28.

Cada religión tiene en su haber un largo elenco de categorías teológicas y espirituales que necesitan ser objeto de un atento chequeo, porque hace tiempo que chirrían en el contexto de la sensibilidad actual de la humanidad, a estas alturas del siglo XXI. Pueden ser, por ejemplo, el “Dios único y nuestro", la unicidad de nuestra religión y de sus misterios, la utopía mesiánica o escatológica soñada por cada religión y los medios y métodos para conseguir verla realizada en la sociedad histórica... y un largo etcétera.

La visión panorámica de la evolución que en este aspecto de la teología del pluralismo ha recorrido el cristianismo, a lo largo de su trabajada historia, muestra un itinerario teológico interior que desemboca espontáneamente en el puerto del pluralismo, siguiendo la evolución de la sociedad civil, que hace tiempo que ha arribó a ese mismo puerto (TEIXEIRA, 2012) ${ }^{29}$.

\section{Conclusión}

La tensa situación derivada de la actual ola internacional de terrorismo religioso hace saltar por los aires la reserva y cerrazón con que habitualmente ha sido tratado el tema del pluralismo religioso, como si fuera un asunto académico, eclesiástico, o clerical, y rompe también la indiferencia con que ha sido mirado desde fuera de las religiones, como si fuera un asunto privado de ellas mismas. La crisis actual revela claramente que los enfoques exclusivistas de las religiones son fermento de conflictos culturales y de violencia religiosa incluso terrorista. La Teología del Pluralismo Religioso se revela como una materia sensible, de especial importancia en la maduración espiritual de las religiones. Sólo atravesando un

\footnotetext{
${ }^{28}$ Durante muchos años Torres Queiruga (2001) trató de justificar un tema de tanta raigambre bíblica como el de la «elección», en línea semejante a la defendida por Gerhard Lohfink y tantos otros escrituristas. Con el avance de su reflexión teológica llegó un momento en que su pensamiento ha madurado hasta proponer que debemos superar y abandonar el tema de la elección.

${ }^{29}$ La exposición sistemática más completa de ese itinerario orgánico de posiciones teológicas a lo largo de la historia del cristianismo, escrita desde América Latina, es la de Faustino Teixeira (2012)
} 
proceso de maduración de conciencia, que lleve a la adquisición de una conciencia pluralista, las religiones van a poder contribuir a la paz, en una era globalizada en la que ya no es posible una coexistencia indiferente, sino una convivencia armonizada.

Esa maduración, concretizada en el cambio de paradigma pluralista que las religiones han de adoptar, se revela de interés civil, social, político y humanitario. Aunque no es un proceso fácil ni será una tarea sin oposición, es necesario dar pasos adelante, con urgencia, para anticipar el futuro de paz inter-religiosa que tanto necesitamos. La sociedad civil debe ayudar, incluso en ausencia o dejación de sus deberes por parte de las religiones afectadas. Está en juego -en el marco más amplio- el futuro de la especie humana, que debe superar este momento crítico en que ya ha iniciado la sexta gran extinción. Las religiones deberían ayudar a la convivencia y ser capaces de catalizar la colaboración de la humanidad en torno a sus grandes intereses actualmente en riesgo creciente. La sociedad civil deberá ayudar, en ausencia o dejación de sus deberes por parte de las religiones afectadas.

\section{REFERÊNCIAS}

ALI, Ayaan Hirsi. Cinco tesis de Ayaan Hirsi Ali. El País, 12 de abril de 2015. Disponible en:

$<$ http://internacional.elpais.com/internacional/2015/04/10/actualidad/1428699981_762 750.html>. Acceso en: 23 de julio de 2015.

ARMSTRONG, Karen. La gran transformación. El origen de las tradiciones religiosas. Buenos Aires: Paidós, 2007.

BERTONE. Congregación para la doctrina de la fe, Declaración Dóminus Iesus. Documentos, comentarios y estudios. Introducción del Cardenal Ratzinger. Presentación de Mons. Madrid: Ediciones Palabra, 2002.

BINGEMER, Maria Clara. Violência e religião. Cristianismo, Islamismo Judaismo, Três religiões em confronto e diálogo. Rio de Janeiro e São Paulo: Editora PUC-Rio e Loyola, 2001. 
BURROWS, William R. Por que não sou herético. Teologia del pluralismo religioso, le acuse, la mia difesa. Bologna: EMI, 2014.

CASPAR, Robert. Para una visión cristiana del Islam. Santander: Sal Terrae, 1995.

ESTADO ISLÁMICO llama a matar civiles en Occidente. Diario El Comercio, Perú, 22 sept, 2014. Disponible en: <http://elcomercio.pe/mundo/terrorismo/estado-islamicollama-sus-seguidores-matar-occidentales-noticia-1758694>. Acceso en: 13 de julio de 2015 .

GANDHI, Mahatma. Sobre el hinduismo. Madrid: Ediciones Siruela, 2006.

GUTIÉRREZ, José Luis (ed.). Doctrina Pontificia. Documentos Políticos. Madrid: BAC (Biblioteca de Autores Cristianos), 1958, passim.

HAYKEL, Bernard. Los dilemas del Islam: la reforma pendiente. Disponible en:< http://internacional.elpais.com/internacional/2015/04/10/actualidad/1428696356_1506 o6.html> El País, Madrid, 12 de abril de 2015. Acceso en: 19 de abril de 2015.

HUNTINGTON, Samuel. El choque de civilizaciones y la reconfiguración del orden mundial. México: Paidós, 1997, p. 280.

SIMPOSIO INTERNACIONAL DE TEOLOGÍA DE LA UNIVERSIDAD IBEROAMERICANA. III Simposio Internacional de Teología de La Universidad Iberoamericana, septiembre 2015, México.

JASPERS, Karl. The origin and goal of History, Connecticut: Yale University Press, 1953 .

JASPERS, Karl. Vom Ursprung und Ziel der Geschichte. Frankfurt: Fischer Bücherei, 1995.

JUNG, C.G. Collected Works, v. 6, Psycological Types. In: BARING, Anne; CASHFORD, Jules. El mito de la diosa. Madrid: Ediciones Siruela, 2005, p. 505.

KEPEL, La Yihad. Expansión y declive del islamismo. Barcelona: Ediciones Península, 2001.

KNITTER, Paul (ed.). The Myth of Religious Superiority. New York: Orbis, 2005.

KUHN, Thomas. La estructura de las revoluciones científicas. México: Fondo de Cultura Económica, 1962, 2000.Edição brasileira: BOEIRA, Beatriz Vianna (ed.). A estrutura das revoluções científicas. São Paulo: Editora Perspectiva, 1998.

MARTÍN VELASCO, Juan de Dios. Metamorfosis de lo sagrado y futuro del cristianismo. Cuadernos aquí y ahora, Santander, n. 37, Sal Terrae, 1999. También en: <http://servicioskoinonia.org/relat/256.htm>. Acceso en: o2 de julio de 2015. 
MELLONI, Javier. El Uno en lo Múltiple. Santander: Sal Terrae, 2003.

PERA, Marcello Pera. Perché dobbiamo dirci cristiani. Milano: Mondadori, 2008

PERA, Marcello. Il Corriere della Sera. Milano: Mondadori, 2008.

PIKAZA, Xavier. Violencia e extremismo no xudaísmo e no Islam. Encrucillada, España, v.39, n.193, p. 8-7, maio-juño 2015.

RATZINGER, J. II Encuentro de Presidentes de Comisiones Doctrinales de América Latina y Caribe. Fe y Teología en América Latina. Bogotá: CELAM, n. 148, 1997.

SALVARANI, Brunetto. Primavera ecuménica e interreligiosa nell'età di Papa Francesco. In: NASO, P.; SALVARANI, Brunetto (a cura di). I ponti di Babele. Bologna: EDB, 2015, p. 83-103.

SESHAGIRI RAO, K.L.. Teología inter-religiosa: una perspectiva hindú. In: VIGIL, J.M. (org.). Por los muchos caminos de Dios: v. V - Hacia una teología planetaria. Quito, Ecuador: Editorial Abyayala, 2010. p. 148-156.

TEIXEIRA, F. Teologia e pluralismo religioso, São Bernardo do Campo: Nhanduti Editora, 2012, p. 191. En español: Teología de las religiones. Una visión panorámica. Quito: Editorial Abyayala, colección Tiempo axial. 2005.

TORRES QUEIRUGA, Andrés Diálogo de las religiones y autocomprensión cristiana. Santander: Sal Terrae, 2005.

TORRES QUEIRUGA, Andrés. El papa pastor frente al restauracionismo preconciliar. I Viva, Valencia, n.190, 2014.

TORRES QUEIRUGA, Andrés. Vaticano III. Cómo lo imaginan 17 cristianos y cristianas. Bilbao: Desclée, 2001.

TORRES QUEIRUGA; SUSIN, L. C; Vigil, J. M (ed.). Pluralist Theology: The emerging paradigm. Concilium, Petrópolis, n. 319, v.1, 2007.

TOYNBEE, Arnold. El cristianismo entre las religiones del mundo, Buenos Aires: Emecé editores ,1960.

VARIOS. Bibliografía en línea sobre nuevos paradigmas. Disponible en: $<$ servicioskoinonia.org/BibliografiaNuevosParadigmas.pdf $>$. Acceso en: 29 de julio de 2015 .

VIGIL, José María. El paradigma pluralista: tareas para la teología. Hacia una relectura pluralista del cristianismo. Concilium, Petrópolis, n.319, v.1, p.39-48, 2007. 
VIGIL, José María. Escritos sobre teología del pluralismo 1992-2012. Libros digitales Koinonía. Disponible en:< http://www.servicioskoinonia.org/LibrosDigitales/ >. Acceso en: 23 de julio de 2015.

VIGIL, José María. Teología del Pluralismo Religioso. Quito: Abyayala 2005, p. 400. Edição brasileira: Teologia do pluralismo religioso. Para uma releitura pluralista do cristianismo. São Paulo: Paulus, 2006, p. 469.

VIGIL, José María. La política de la Iglesia apolítica. Una aportación a la teología política desde la historia. Valencia : Edicep, 975.

VIGIL, José María.. Teología del pluralismo religioso. Quito: Editorial Abyayala, 2006, p. 41-48.

WARRAQ, Ibn .Por qué no soy musulmán. Barcelona: Ediciones del Bronce, 2003. 